\title{
English(es) in College English Textbooks in the Philippines
}

\author{
Alejandro S. Bernardo \\ University of Santo Tomas, Manila, Philippines
}

\begin{abstract}
Although a great deal of research on $\mathrm{PhE}$ (Philippine English) has been initiated and published, its presence in instructional materials and other contentious issues relevant to the existence of varieties of English seems to be marginally tackled in locally printed learning paraphernalia, particularly college English textbooks. A cursory review of literature suggests that at the moment, very few studies that examine the varieties of English represented in textbooks have been undertaken in the local setting. This study, therefore, presents the results of a content analysis of college English textbooks from three leading Philippine universities to identify the standard(s) promoted in teaching and internalizing the rules of English grammar and to pinpoint the norm that authors adhere to writing textbooks. The content analysis of three college English textbooks hints at the assumption that English(es) or varieties of English are rarely extensively reflected and discussed in local college English textbooks and that Filipino textbook writers do not seem to strictly adhere to an exogenous norm, e.g., AmE (American English). The analysis shows that English textbook developers, who are also English teachers, use distinctive PhE grammatical structures in writing books. This makes them propagators of a pluricentric model, i.e., two varieties. In this study, these varieties are American and Philippine English(es).
\end{abstract}

Keywords: content analysis, PhE (Philippine English), pluricentric model, World English(es)

\section{Introduction}

A great deal of research delving into the existence of a local variety of English in the Philippines (Bautista, 2011; Bolton \& Bautista, 2008) is undoubtedly very useful in revealing the phonological, morphological, and syntactic variations in PhE (Philippine English). Research findings of corpus analysis (Alonsagay \& Nolasco, 2010; Bautista, 2000, 2001; Borlongan, 2008, 2011; Dita, 2011; Gustilo, 2011; Tayao, 2008) evidently show that $\mathrm{PhE}$ has its own phonological, lexical, and syntactic peculiarities propagated by the circle of educated Filipino speakers, e.g., media practioners, educators, and college learners. The authoritative conclusions of both local and foreign researchers who devoted their time to studying $\mathrm{PhE}$ imply that, indeed, there is a localized and an indigenized variety of English that aptly mirrors the sociolinguistic and sociocultural realities in Filipino speech communities.

Although a large amount of investigations on $\mathrm{PhE}$ have been initiated and published, its presence in instructional materials and other contentious issues relevant to the existence of varieties of English seem to be marginally tackled in locally printed learning paraphernalia, particularly college English textbooks. A cursory review of literature suggests that at the moment, very few studies that examine the varieties of English

Alejandro S. Bernardo, Ph.D., Department of English, Faculty of Arts and Letters, University of Santo Tomas. 
represented in textbooks have been undertaken in the local setting. Stated in another way, the escalating significance of different English(es), particularly the legitimate nativized varieties, appears to be barely mirrored in the design of ELT (English Language Teaching) curriculum and production of instructional materials such as textbooks.

This study therefore presents the results of a content analysis of locally printed college English textbooks from three leading Philippine universities to identify the standard (and the culture that goes with it) promoted in teaching and internalizing the rules of English grammar and to pinpoint the norm that the textbook authors themselves adhere to in writing. One very important question guided the textbook analysis: Which variety(ies) of English is introduced in college English textbooks published in the Philippines? Both implicit and explicit hints of different varieties of English therefore were examined. Textbook writers' usage of preferences are inspected to detect if they are strictly fastened to an exonormative model, e.g., AmE (American English), and if distinctive features of the local variety, PhE, are observable in their own writing. Textbooks on grammar and writing were analyzed primarily because learners assimilate and conform to what they overtly or implicitly promote or purport. As how Uittamo (2009) eloquently put it:

Textbooks have a significant role in language learning and teaching... they should be the student's objective guide to the target language and culture. Moreover, textbooks are responsible for creating an image of the language, culture and societies where this language is used. Students may rely heavily on this information when they learn and it is therefore important to study textbooks in order to find out what kind of ideologies, images and information they offer students, and whether or not this information is updated and objective. (p.11)

Johansson (2003) added that textbooks are portrayals of the curriculum and are a tie between curriculum and pedagogy. Similarly, Dayag (2010) construed that what transpires in the classroom are mirrored in textbooks, and these consist of the teacher's input and activities. Therefore, it may be reasonably posited that textbooks are indispensable tools for knowledge acquisition and not just an expensive commodity in any educational setting.

While the aforementioned simply entails an identification of the pedagogical standard promoted in local English textbooks, an analysis of the organizational structure, themes, and pedagogical approaches, and culture(s) represented in three textbooks, as will be shown in the succeeding section, was also conducted for the findings might provide invaluable input in the future design of textbooks for teaching English. Condensing the abovementioned in a statement of objectives, this paper primarily aims to describe the content, organization, approach, and norm(s) adopted by locally published college English textbooks. More specifically, it endeavors to address the following research questions: (1) What topics or themes are covered in college English textbooks?; (2) How are college English textbooks structured or organized?; (3) Which variety or varieties of English are introduced in college English textbooks?; and (4) How do locally published college English textbooks reflect issues relevant to the existence of varieties of English?.

\section{Method}

Following the framework used by Dayag (2010) when he examined PhE in college oral communication textbooks, this study also adopted the bottom-up approach and undertook a content analysis. Content analysis as a research method is a systematic and objective means of describing and quantifying phenomena and is known as a method of analyzing documents (Elo \& Kynga, 2008). The purpose of which is to generate concepts or 
categories which help construct a model, conceptual system, conceptual map, or categories. In further examinining the textbooks, Uittamo (2009) and Matsuda's (2002) frameworks for analysis were also followed. Uittamo (2009), suggested that in analyzing textbooks, one must: (1) find out how the English-speaking world is introduced and what kind of an image of it is created; (2) find new material and updated approaches to the spread of English in the world information about global English; (3) identify which varieties of English are introduced and which cultures are introduced; (4) spot implicit and explicit hints of different varieties of English and which English-speaking countries and cultures are mentioned or introduced in textbooks; (5) describe the kind of image of native speakers and nonnative speakers created in textbooks, and (6) decide whether or not stereotypes are reinforced. Matsuda (2002), on the other hand, recommended a careful look into: (1) English textbooks' organizational structure and parts; (2) the kinds of people represented; (3) the culture(s) represented; (4) the kinds of English uses represented; and (5) prominence of the presentation of the international and intranational use of English.

Initially, the variety(ies) of English represented in the three textbooks were identified and how they can be recognized were examined. Both implicit and explicit hints of different varieties of English were studied. Syntactic rules and corresponding illustrative examples and usage preferences in these books were observed to detect if they follow a foreign norm and if distinctive features of the local variety are apparent in them. For purposes of anonymity, however, the titles and authors of the books remain undisclosed. In the presentation of results, the textbooks were simply coded as TB1 (Textbook 1), TB2 (Textbook 2), and TB3 (Textbook 3).

The sentences that bear distinctive structures were culled verbatim from the textbooks page-by-page and positioned alongside their equivalents in SAE (Standard American English). In conjecturing their SAE counterparts, Quirk, Greenbaum, Leech, and Svartvik’s (1985) comprehensive grammar of the English language and a university English teacher and former publication editor were consulted.

\section{Results}

\section{TB1}

Organizational structure. TB1 lessons, from the first to the last, commence with concept maps that schematically provide overviews of the lessons covered. These concept maps are followed by sets of objectives that stipulate what the learners are expected to accomplish or master at the end of the lessons. The section titled "Beginning Task" serves as lesson starters that either arouse the learners' interest or activate their schema or prior knowledge. The discussion section provides explanations or inputs for all the skills, language, and grammar foci. At the end of every discussion are activities that allow the learners to apply their acquired knowledge of the target concept in specific tasks - whether in written or spoken forms. These activities include pair tasks, text analyses, listening exercises, individual writing tasks, reading comprehension exercises, library work, online exercises, interviews, group work, role playing, composition writing, field work, filling out graphic organizers, impromptu speaking, drawing, and listening to radio and television commentaries. As a culminating activity, the students are asked to reflectively fill out the self-assessment forms that require them to state how the lessons have helped them hone their competencies. The final segment of each lesson presents a summary of key points espoused and helpful study tips to consider. 
Themes and pedagogical approach. A closer analysis of the 15 lessons shows that the four units of TB1 are anchored on the following themes: (1) handling and dealing with the demands of college life; (2) enhancing language and communication skills; (3) addressing the expectations of the disciplines; and (4) enhancing competencies by applying critical thinking skills in real-life situations. The approach in teaching these themes, according to the authors, is highly interactive, i.e., the activities allow the learners to perform in groups or in pairs and are learner-centered, for there are individual tasks that aid the users in assessing their level of improvement in their learned competencies. Further, each of the 15 lessons follows the integrative design. Stated in another way, each lesson incorporates reading, speaking, grammar, writing, and listening. The reading, speaking, and writing tasks seem to be shaped by the texts that learners are asked to peruse.

Grammar points or forms are culled or deduced from the selections, e.g., essays and other types of expository texts. In other words, the texts dictate the grammatical structures to be taught and learned. These include capitalization and punctuation marks, verbs and verb tenses, word analysis, compound words, direct quotes, subject-verb agreement, pronoun-antecedent congruence, phrases and clauses, collocations, types of sentences according to structure, direct and reported speeches, sentences according to form, adjectives, passive and active voice, prepositions, locatives, sequence signals, subjectivization and nominalization, verbals, types of questions, and hedging devices. In a good number of lessons, this is illustrated by the statements lifted verbatim from the texts which the students are asked to analyze to arrive at a certain generalization or a linguistic rule; thus, the approach is inductive as shown in the Example 1:

Example (1) Read the following sentences which were lifted from the text:

If you develop good study habits, you will also develop good test-taking skills.

Remember this rule:

When the sentence expresses a condition that may exist or may happen, the verb in the if-clause is in the present, and the verb in the main clause may be in the future tense or present tense.

In a few cases, however, the sentences for analysis are not directly lifted from the reading selection (see Example 2):

Example (2) Read the following text:

Yesterday, I met some of my friends whom I have not seen for some time. I invited him to a restaurant and there we had fun recalling the their days together. They agreed to meet at least once a month to rekindle our friendship.

Did you see the errors in the text? What are these errors? Did you note the following?

It may be deduced, however, that in some instances, grammar is taught deductively. Put more simply, the rules, principles, concepts, or theories are presented first, and then their applications are treated. This approach is illustrated in Example 3 below:

Example (3) Compound subjects joined by and but are not considered one unit require plural verbs.

For example: The Dean and the Assistant Dean work together to achieve the goals of the college.

While it seems evident that TB1 employs both the inductive and deductive grammar teaching, it could be said that TB1's approach to grammar instruction is rule-driven. In such an approach, a grammar rule is explicitly presented to the learners and followed by practice applying the rules. It must be underscored, however, that the 
rules are explicitly stipulated in TB1, and the students are not asked to formulate the rules by themselves.

Culture(s) represented. The analysis of the texts used as springboards for teaching grammar lessons and other macroskills shows that there is a preponderance of locally authored focus selections. Fifteen out of the 20 reading texts found in the book were written by Filipino essayists, researchers, and educators and published in some of the leading broadsheets in the Philippines, e.g., Panorama, Manila Bulletin, Philippine Star, Philippine Daily Inquirer, and Manila Times. Only five were written by foreign writers.

In explaining grammar items and rhetorical conventions, it appears that an exogenous norm is observed as suggested by the use of English grammar books written and published in inner-circle countries, e.g., Cambridge, Macquarie, Barron's Educational Series, Inc., McGraw-Hill, Inc., Bedford; Edward Arnold Ltd., Oxford University Press, English Language Program Division, United States Information Agency, University of Michigan, and Houghton Mifflinn Company. Further, in TB1's lesson on writing bibliographic entries, the examples provided are publication details from a number of foreign books. Grammar books written by English language gurus, like Celce-Murcia and Larsen-Freeman are among the primary references, and it seems that no local textbooks and reference books on grammar teaching and composition writing was consulted in designing the lessons.

Further analysis of TB1 indicates that there are a few specific instances of inconsistencies, particularly in spelling. For example, the AmE “catalog” and British English "catalogue” both appeared in one lesson. Thus, TB1 probably does not conform to a single variety of English (e.g., AmE) because of the observed inconsistencies.

It is interesting to note that local culture, in some way, is represented when sentences for analysis were crafted (see Example 4):

Example (4) Rice and fish is the staple food of most Filipinos.

If you were the mayor of Manila, how would you enforce cleanliness to make Manila as clean as Marikina and Singapore?

In addition, a closer examination of TB1 suggests that there is an overt attempt to introduce the framework of World English(es) and an array of sociolinguistic issues brought about by the constant use of English in both local and foreign stadia to students. The local variety of English as well as norm selection is discussed in one of the lessons. It must be noted, however, that very few tasks or activities that facilitate in-depth or profound discussions of these contentious language issues are provided. The learners are simply asked to answer comprehension questions about the texts read. It seems that it is the prerogative of the teachers to provide more tasks and separate comprehensive discussions of issues material to English language learning and teaching in the Philippines.

\section{TB2}

Organizational structure. TB2 is divided into nine chapters, and Chapters 1-7 begin forthwith with inputs about the topics to be covered and end with enrichment exercises. Between the inputs and the enrichment exercises are study questions that assess the learners' understanding of the concepts provided. Similar to TB1, the discussion section of Chapters 1-7 of TB2 offers an explanation or a clarification of a concept, e.g., description of a process, definition of terms, reports, and figures and data, critical thinking, the art of reading, and non-prose 
forms, that students need to comprehend. The study questions are merely interrogative statements that check students' comprehension of the preceding texts, selections, or linear and nonlinear information, while the enrichment exercises include tasks such as paragraph or essay writing, puzzle making, paraphrasing and summarizing an excerpt, and peer editing, which give the students opportunities to reinforce or extend their learning, i.e., help with transfer of learning.

The next chapter of TB2, Chapter 8, features seven reading selections. The activities that follow include answering reading comprehension questions, prewriting tasks, during writing tasks, and post-writing or revising tasks. The prewriting tasks include pair work, group work, role-plays, outlining, brainstorming, question inventory, conducting interviews, figure analysis, gap-filling exercises, listening to news and broadcasts, and speech writing. The writing tasks include writing prompts and individual writing assignments, e.g., writing one-paragraph summaries, essay writing, and one-paragraph paraphrases, while the post-writing or revising tasks contain peer revision questions and guidelines for editing. The peer and self-editing tasks aim to assist the students in improving their compositions, content and form wise. At the end, the students are required to submit their revised compositions for grading or marking.

The last chapter of TB2, Chapter 9, features another collection of selections which students may read in addition to the reading texts they are provided with. These materials were borrowed from a variety of sources like books, magazines, and newspapers with the hope that when the target users read them, their love for reading will be rekindled and their writing skills will be further honed.

It was found, however, that TB2 hardly uses typical openers like previews or overviews and learning goals or objectives and usual closing like self-reflection tasks or summaries of concepts learned, unlike TB1.

Themes and pedagogical approach. TB2 is a reading-writing textbook that caters to college students taking up majors like education, communication arts, psychology, accounting, and business among others. A closer look at its subdivisions shows that the lessons center on the following themes or competencies: critical thinking, creative reading, understanding non-prose forms, observing the process approach to writing, understanding the considerations in writing, applying discourse and rhetorical moves, revising, and refining one's work.

Further examination of TB2 indicates that it follows the traditional college textbook design in which input is provided at the beginning of each lesson and an output (or outputs) from the learner is expected at the end. It may also be deduced that TB2 observes the "application principle" (Merrill, 2002) in textbook writing in which learning is promoted when learners apply the new knowledge in student and task-centered instructional strategies or activities. It is necessary to note, however, that unlike TB1, TB2 barely integrates formal and explicit grammar instruction in all its lessons. It is expected, therefore, that grammar is taught separately in another allied college English course and that a different textbook is used in teaching and learning linguistic rules. When a number of teachers were asked, they claimed that they do not prescribe any specific textbook for the grammar component of the course; thus, the teachers utilize various foreign and local sources. Unfortunately, these instructional materials were not analyzed.

Culture(s) represented. The analysis of the selections featured in TB2 suggests that there is a preponderance of locally authored reading texts which deal with a wide-range of local issues at the time the book was released, e.g., medium of instruction in schools, teenage pregnancy, date rape, language as an indication of 
class distinction, cellular phone fads, and jealousy. Two of the articles, in fact, were written by two past presidents of the Philippines. Almost all, 12 out of 13, selections were written by Filipino authors. Further, these articles were reprinted with permission from local dailies like The Philippine Daily Inquirer, The Philippine Star, Philippine Panorama, and Sunday Inquirer Magazine. It should be noted, too, that TB2, unlike TB1, hardly introduces the framework of World English(es) and varied sociolinguistic issues, that is, only two of the selections tackle contentious issues like the constant use of English in the country. The first overtly promotes English as the primary medium of instruction and equates the mastery of English with college degree and living a better life, while the other looks English as an indicator of social class.

It is also important to note that TB2 uses illustrations and examples drawn from the local context. In two of the lessons, for example, a special power of attorney written by a Filipino lawyer and enrollment data of a local university are used. In other lessons, local colors like Kabataang Barangay, shopping in Greenhills, the song Nanghihinayang, local text messaging humor, Abbu Sayaff, Manila, and Mayon Volcano are mentioned. In other words, the western or native speakers' culture — even western rhetorical conventions — are hardly mentioned in TB2 although based on the list of references used, the authors also consulted foreign books published by DC Heath and Co., Allyn and Bacon, McGraw Hill Inc., and NTC Publishing Group. TB2, which is a writing textbook, scarcely introduces Western rhetoric to Filipino college learners.

A deeper look at TB2 also suggests that the norm to be used when students edit their peers' compositions is not unequivocally recommended. The editing guidelines for verb tenses, subject-verb agreement concord, spelling, punctuations, pronoun-antecedent relationships, and vocabulary do not specify which standard—British, American, or Philippine English—must be used. It seems reasonable to assume that the students have a default norm to adhere to in language editing. This default norm, however, appears inexplicitly identified.

In addition, the seven authors of TB2, all of whom are Filipinos, seem to write following AmE as the norm. The words pieces of evidence, cope with, cocurricular, toward, based on, result in, and favor are an indication of adherence to AmE. However, there are local vocabularies such as balikbayans, sampayan windows, re-becoming, adobo platter, and kidnappings that appear in some of the essays included in TB2.

Finally, some inconsistencies in spelling and punctuation are noticeable in TB2. For instance, editor-in-chief and editor in chief both appear on the acknowledgement page and judgement and judgment are both used in two different chapters.

\section{TB3}

Organizational structure. Three units comprise TB3. The first unit is divided into four lessons, while the second and the third cover only one lesson each. Every lesson is comprised of tasks sequenced in the following order: listening task, reading task, language task, speaking task, and writing task. It must be mentioned that TB3, which basically is a grammar textbook, commences with a succinct review of the different parts of speech through diagrammatic presentations. In the review of nouns, for instance, a question (in the case of other parts of speech, a chain of questions is given) is posed and the answer to it immediately follows, e.g., Does the word give a name to a person, a group of persons, a place, a thing or event?... Then it is a noun. Categories of nouns are then enumerated and what opposite them are a number of examples. As a grammar exercise, ten sentences are given after the review of each part of speech, and the students are asked to simply underline the nouns, pronouns, 
verbs, adjectives, adverbs, prepositions, conjunctions, and interjections found in the sentences.

The listening tasks of TB3 typically include listening to the teacher's instructions and listening to the teacher as he/she orally reads texts such as poems, short paragraphs, short stories, and dialogs. After listening, the students are directed to complete listening comprehension activities such as telling whether a statement is true or false based on what was heard, arranging events in chronological order, classifying words based on the selection listened to, filling in the blanks, identifying places in a logical space sequence, noting details or information, and echoing and reformulating a speaker's message.

TB3 also fosters the students' reading skills by asking them to read selections like formal essays, narratives, and other text types and to answer vocabulary enrichment exercises, e.g., identifying word meaning through context clues and comprehension questions classified as literal, interpretative, and applied, by providing inputs about a reading concept, e.g., reading terms such as skimming and scanning, and by requiring the learners to accomplish several reading exercises.

The language tasks, on the other hand, present sentences for analysis culled verbatim from the focus reading texts. From these sentences, linguistic rules are formulated or presented, which later on are applied in written grammar exercises. It is worthy of note that the grammar lessons in TB3 match the English Plus course contents prescribed by the CHED (Commission on Higher Education). The grammar lessons include subject-verb concord, pronoun-antecedent agreement, verb tenses, direct and reported speech, mood, coherence through proper place of adjectives and adverbs, emphasis in the sentence through coordination, subordination, appositives, adjective clauses, position, periodic sentence, climactic order, parallel structures, conciseness, active and passive voice, and contrast.

The linguistic rules that students are expected to assimilate under the language task section of TB3 are further applied in a range of speaking and writing tasks. Instructions, e.g., observe agreement of subject and verb; agreement of pronoun with its antecedent, are explicitly stated before the textbook users work on the assigned speaking tasks such as talking about one's self, talking about a certain topic in class, and writing about a specific theme. Other speaking tasks include relating to the class cases similar to the main characters in the selection read, role-playing, information gap, dyadic activities, interviewing, poem recitation, oral reading of sentences, and oral exercises on emphasis.

Each lesson in TB3 ends with individual writing tasks which include writing news articles, developing topics, writing a five-sentence paragraph, composing a speech, and writing interview transcripts in paragraph form.

Themes and pedagogical approach. The analysis of TB3 shows that it puts premium on the qualities that characterize a good sentence: unity (Unit 1), coherence (Unit 2), and emphasis (Unit 3). As claimed by the authors, the lessons offer college freshman students ample opportunity to hone their basic communication skills through listening, reading, language, speaking, and writing tasks. Hence, it is reasonable to posit that TB3, like TB1, follows the integrative design. Furthermore, as stated earlier, the book embodies the contents of CHED's prescribed outline for an English Plus course, namely: a vocabulary to prepare the first year students for academic study, and a grammar to enable them to perform varied communicative functions.

It is also imperative to underscore that similar to TB1, the grammar points taught in TB3 are dictated by the selections or texts that students are required to thoroughly read. As expected, the model sentences for analysis are lifted verbatim from them, and out of these sentences, linguistic rules are generated thus following the inductive 
approach to grammar teaching. Stated in another way, TB3 provides students with samples of language, and they have to come to an intuitive understanding of the rule. This approach is illustrated by the following cases (see Example 5):

Example (5) (a) Can you draw the rule applied in each set of examples?

Father feels he has been working too hard.

(b) Study the sentences and find out how the past perfect tense is used.

Delia had sold her hair before she bought the platinum.

A thorough analysis of TB3 would also suggest that in a good number of grammar lessons, grammar is taught deductively, i.e., linguistic rules are presented first, and these rules are applied in specific cases. In other words, the grammar rule is presented and the learners engage with it through the study and manipulation of examples. In TB3, this approach is illustrated in the following cases (see Example 6):

Example (6) (a) The future tense indicates an action or condition that will take place at a time to come. This tense may takes [sic] different forms.

Ordinary Form (shall or will + present simple form of the verb):

I shall look forward to having some artificial intelligence.

(b) Other expressions that may intervene between the subject and the verb are: with, together with, besides, as well as, etc.. Their objects do not affect the number of the verb.

For example: Mr. Paz, together with his wife and children, plans a summer vacation.

Therefore, similar to TB1, TB3 employs both the inductive and deductive approaches to grammar teaching. This choice of design also lends TB3 to adhere to rule-driven grammar instruction. It is interesting to note, however, that TB3 tolerates the use of unconventional grammar rules (see Example 7):

Example (7) Everyone and everybody may take plural verbs when used in informal speaking, thus:

Everyone notice the children's politeness.

Everyone implored the Almighty for their daily family needs (informal speaking).

Culture(s) represented. The examination of the texts used as takeoff selections for teaching reading, language, speaking, and writing implies that TB3 highly favors local authors as echoed by the predominance of locally published selections. Thirteen were written by Filipino essayists, columnists, and researchers and were adapted from local publications such as the Philippine Panorama, Health and Home, the Philippine Daily Inquirer, the Philippine Sociological Review, and the Philippine Research. Only nine texts authored by foreign writers are featured in TB3.

The presentation of the grammar rules gives the impression that an exonormative standard is well promoted as indicated by the use of reference books published in inner-circle countries, e.g., Reinhart and Winston, G.K. Hall and Co., Oxford University Press, Wadenworth Publishing Co., and Prentice Hall. Hence, no locally printed grammar books were consulted in writing TB3. The consistent use of expressions or words such as toward, pieces of luggage, resulted in, dispose of, and based on perhaps are indications that the five Filipino authors of TB3 hold fast mainly on the so-called Standard English variety.

A more profound examination of TB3 would also show that the local culture is highly favored. Topics like traditional Filipino values, Filipino family, local destinations like Baguio, local characters and names like Kabayan, balikbayans, Malacanang Palace, bancuro, Visayans, Tagalogs, Tagaytay, Batangas, Luneta, Badjaos, 
Philippine papaya, Tawi-tawi, Zamboanga, Callao Caves, Maria Clara, Rizal, Noli Me Tangere, Leonora Rivera, Banaue Rice Terraces, and local bamboo are found in TB3. Very few terms that are representative of foreign cultures, e.g., Leonardo da Vinci, Prince Charles, Princes Diana, and Taj Mahal were cited.

Unlike TB1, TB3 hardly tackles issues material to English language learning and World English(es). However, it is worthy of note that a number of PhE terms appear in TB3. Examples of these are bold movies, kaingeros, barrio, and betamax culture. Moreover, in terms of spelling inconsistencies, the words dialog, dialogue, single-word (adverbs) and single word (adverbs), bio-prospectors and bioprospectors and everyday (used as an adverb) and every day are found in TB3. This seems to indicate that spelling and grammar inconsistencies may have resulted from the use of two varieties of English. Finally, the serial comma in listing is found inconsistently used as seen in Example 8:

Example (8) (a) Aside from those mentioned in the selection, how can the new technology adversely affect the social, spiritual and moral life of the people?

(b) Throughout life, the very cells of which we are composed of, undergo a process of aging in which they lose their ability to divide, reproduce, and replenish.

\section{English(es) in TB1, TB2, and TB3}

An examination of the statements culled verbatim from the three textbooks and positioned against the expectations of the so-called SAE would show that Filipino writers use distinctive grammatical structures. These sample-structures are clustered below.

\section{Word order.}

Unusual word positioning.

(1) You can only do this by being able to take down notes effectively no matter how much information you get each day. (TB1)

(2) Dr. Milagros Ibe (1981) defined also a test as "a sample behavior under controlled or specified conditions and aimed toward providing a basis for forming judgments”. (TB1)

(3) Develop also the habit of rewriting your notes. (TB1)

(4) But an in-depth discussion of the text can only be done through the why and how queries which allow you, the reader, to form expectations about the text, and either conform or reject ideas through critical evaluation. (TB1)

(5) Use also words that have a positive connotation. (TB1)

(6) The present continuous form may be used also to express future activities. (TB3)

(7) The missionary was responsible also for the publication of Catholic Digest. (TB3)

\section{Unusual word order.}

(1) Salvador, composed a speech in 45 minutes about his struggles as a student-teacher. (TB1)

(2) Read this time the numbered instructions. (TB1)

(3) Ordinary commands are put in the infinitive form and are usually introduced by such word as told. (TB3)

Prepositional usage.

Omission of preposition.

(1) They provide you [with] enough information that you can easily picture in your mind how the story begins and ends; how the characters interact; how a place looks like and a lot more. (TB1) 
(2) Group yourselves into three. Provide your classmate [with] the procedure on how to do something. (TB1)

(3) Distinguish [among] insinuations, connotations, and presuppositions. (TB1)

(4) But an in-depth discussion of the text can only be done through the why and how queries which allow you, the reader, to form expectations about the text, and either conform [to/with] or reject ideas through critical evaluation. (TB1)

(5) I can now differentiate [between/among] fallacies and avoid using them. (TB1)

(6) During a 90-minute session on her multimedia computer, Sue watched two prominent historians debate [about] economic issues. (TB2)

(7) Fill [in] the blank with the appropriate pronoun. (TB3)

(8) Can Archie's parents be accused [of] and punished for child abuse and exploitation? Explain your answer. (TB3)

(9) As you listen, fill [in] the blanks with these unforgettable moments that have kept the writer alive and have brought him peace all these years. (TB3)

(10) Fill [in] the blanks with the present perfect tense of the verb in the parentheses. In some sentences, place the modifier between the helping verb and the main verb. (TB3)

(11) I am contented [with/in] where I am. (TB3)

(12) As I sought knowledge, what have I wished [for]? (TB3)

Wrong preposition in a verb/adjective + preposition combination.

(1) The materials in the library are classified in two ways... (TB1)

(2) Check out the boxes and state your answers. (TB1)

(3) But isn't it going to be more helpful if the focus should be shifted not on determining adolescent depression but on preventing its occurrence? (TB1)

(4) Keep control of the interview by not allowing the interviewee to veer away from the topic or run away with the interview. (TB1)

(5) Compare them now to the following sentences. (TB1)

(6) Are Filipinos still enjoying a great advantage compared to their Asian brothers and sisters where English is concerned? (TB1)

(7) Continue writing for about five minutes more. Save what you have written for your portfolio. (TB1)

(8) Decide on a topic and then fill up this grid. (TB1)

(9) Read the descriptive process essay on Taking a Blood Sample. (TB1)

(10) You may prepare a diagram and include the different landmarks one should watch out for. (TB1)

(11) The employer told the applicant, "Fill up the application form". (TB3)

(12) Mount Kinabalu is an infant compared to the 10 million-year-old Himalayan. (TB3)

Wrong preposition in prepositional phrase as adverbial. A series of adverbs, the general, follow a pattern. (TB3)

\section{Wrong preposition in prepositional phrase linked to noun.}

(1) Make an annotated bibliography using the references you have gathered in Activity 3 on television. (TB1) 
(2) Using the timetable below, draw up your own schedule for the week and make certain that you create a balance with your activities at home and in school. (TB1)

(3) Work with a classmate. In the essay of J. Michael Bennet on How to Build a Power Vocabulary, identify the different kinds of sentences used based on function and structure. (TB1)

(4) Do you have an answer for No. 3? (TB1)

(5) Ok, let's go to class early and see if your classmates have an answer for it. (TB1)

(6) Your teacher will assign one journal article for your reading. (TB1)

(7) This involves the participation of the group members on what to do and how to do things. (TB1)

(8) The cause for the reduced birth rate in Thailand and Indonesia is poverty. (TB3)

(9) Observe agreement of subject and verb; agreement of the pronoun with its antecedent. (TB3)

(10) Transform the sentences from the previous page into simple affirmative questions, then answer them with short affirmative or negative replies. (TB3)

(11) Since-denotes from a point of time in the past to a point of time in the present. (TB3)

(12) Discuss further your arguments to the shepherd's proposal if you were the nymph. (TB3)

(13) What could be the implication of this discovery on world population? (TB3)

\section{Inserted preposition.}

(1) Good! Can I call on you later then? See you in class. (TB1)

(2) Journalistic texts use more of compound words and phrasal verbs while literary texts employ more of metapohorical terms. (TB1)

(3) They were working on simultaneously on the project. (TB3)

(4) As your instructor reads the selection, try to find out under in which area the change will fall. (TB3)

(5) For-expresses of duration or length of time. (TB3)

\section{Perfect tenses.}

Present perfect for past. Write a report on an event or activity you have been involved in last summer. (TB1)

Modals.

Past form for the present form.

(1) One partner would use the card catalogue; the other will use the on-line program. (TB1)

(2) Throughout your college life, you will find yourself in situations where your leadership qualities would be of much use. You would be required to work with different people coming from different kinds of background who would be bringing with them different attitudes, personalities, and dispositions... You would need to be an effective team player yourself... Tact is a characteristic that would be most useful for there will be much sharing of opinions and ideas. (TB1)

(3) This style would make everyone in the team feel he/she is a part of it. (TB1)

\section{Subject-verb disagreement.}

(1) Hermosa (2002) identified this structure with content-area materials (usually academic readings) that needs to tell, show, explain or describe any concept. (TB1)

(2) One of the experiments, in which a mixture of dead-virulent and live-nonvirulent bacteria were injected, produced startling and puzzling results. (TB1) 
(3) It is a white, five-storey, concrete structure built at the slopes of a mountain that overlook the province of Cebu... It looks more like a sprawling bungalow because of its numerous rooms that includes two conference rooms, a chapel, two dining rooms, a meditation room, and offices for the Sisters who own and take care of it. (TB1)

(4) Note that Formal and Informal English refers to the styles of expression. One is not more correct than the other. (TB1)

(5) As for the Humanities, analysis and argumentation is most often required. (TB1)

(6) Through the analysis of the interview transcriptions, findings show that majority of the student teachers prefer the alternate use of both Filipino and English inside their classrooms, which defy the actual designation of media of instruction. As science and mathematics teachers, English should be the only medium in their classrooms. (TB1)

(7) These results have great implications in the present implementation of the bilingual policy as science and mathematics teachers have determined through their shared experiences that the use of English only in their classrooms have not been effective and productive in the long term. (TB1)

(8) The teaching of critical thinking in the minds of philosophers such as Ennis Paul and McPeck and psychologists Sternberg and Fernstein have further identified the components of this educational phenomenon. (TB1)

(9) Everyone notice the children's politeness. (TB3)

(10) The world bank give priority to the third world countries. (TB3)

(11) The Christian world can not accept the research result even if (even though, although) the moral issues on it has been resolved. (TB3)

Pronoun-antecedent disagreement.

(1) The list may be placed all on one piece of paper, arranged alphabetically or they may be placed in index cards ( $3 \times 5$ inches). (TB1)

(2) Anyone is free to express their opinion or ask a question in an open forum. (TB1)

(3) If anyone is ready to board the bus, then they should bring their luggage to the conductor. (TB1)

(4) Furthermore, the book embodies the content of the CHED's recommended outline for an English Plus course, namely: a vocabulary to prepare freshman students for academic study, and a grammar to enable him to perform communicative functions. (TB3)

(5) The family rides the van on its trip to Baguio. (TB3)

(6) Two years is just the period in a child's development when it enjoys "talking" on the telephone and learns that every object has a specific purpose. (TB3)

(7) Everyone implored the Almighty for their daily family needs. (informal speaking) (TB3)

Articles.

Missing indefinite article for a count noun.

(1) The present tense is used to convey an action, [a] state of being, or a fact that is happening at the present time. (TB1)

(2) The future tense conveys an action or [a] situation that will happen in the future. (TB1)

(3) One way of gathering data is through [an] interview. Exclamatory sentences are used to express strong feelings and they use the exclamation point and are expressed using higher intonation. (TB1) 
(4) Two incidents or occurrences following each other may not be directly related, so it is not right to assume that events always follow [a] causal relation. (TB1)

(5) Another strategy that utilizes critical thinking is the use of [a] good argument. (TB1)

(6)... but also to the readers of a writer's message which is conveyed through a letter, [a] news article, [an] advertisement, [an] essay, or the like. (TB2)

(7) [A] Discourse is a coherently-arranged, serious, and systematic treatment of a subject in writing or speaking. (TB2)

(8) Examples and illustrations can likewise be used to support a claim or [an] argument.

(9) For another example of [a] summary, see the concluding part... (TB2)

(10) Does the word express [a] strong feeling or emotion (pain, joy, surprise, contempt, etc.)? (TB3)

(11) Migrants of either sex whose migration is a result of [a] personal choice are more successful in the foreign land than those who follow family members' decisions. (TB3)

(12) The simple present tense is used to denote [a] habitual action. (TB3)

\section{Missing definite article for a specific reference.}

(1) Through [the] interviews conducted with sixteen student teachers from two leading teacher training institutions in the Philippines, the findings yield that [the] student teachers have difficulty in adhering to the bilingual policy of education. (TB1)

(2) Recast these sentences. Make sure the underlined word occupies [the] subject or left-of-center position. (TB1)

(3) [The] Enhancement of the ability of students to think is a fundamental aspect of instruction at all school levels. (TB1)

(4) A recent article titled "A Nation in Crisis: The Pitfalls and Prospects of Reforming Philippine Education” which was published in The Educator, says:

Considered a basic human right, education is mandated by the law to be subsidized by [the] government up to the secondary school levels. But given [the] government's limited budget and the already gargantuan task of providing enough classrooms, teachers, and textbooks for some 18 million students a year, we have failed to address the need to provide quality education. (TB1)

(5) [The] Main ideas of an outline are indicated by Roman numerals and placed farthest to the left. (TB2)

(6) Write a paragraph on a topic interesting to you and edit your own work first. Then have your work edited by your peers. After [the] peer revision, type, proofread, and finalize your paragraph. (TB2)

(7) The earlier we are reconciled to it the better for us. At the turn of the century, the Americans conquered the Philippines and brought with them a public school system, with English is [the] medium of instruction. (TB2)

(8) [The] Use of multimedia in distance-learning is discouraged because of the expense it entails. (TB2)

(9) Which of the list of text messages do you like [the] most? Why? (TB2)

(10) The mode of Charter change is the exclusive prerogative of [the] Congress. (TB2)

(11) I shall work with [the] Congress, civil society groups and local government executives... (TB2)

(12) I ask [the] Congress to pass the Pre-Need Code to rehabilitate, reform and regulate the pre-need educational programs... (TB2) 
(13) Studies, both earlier and current, have noted the importance of the family in the lives of Filipinos and in [the] Philippine society as a whole. (TB3)

(14) Moreover, [the] income per capita in these migrants' households in the Philippines is significantly lower than in the case of respondents who personally decided to move... (TB3)

(15) [The] Careful use of tense helps one understand what event happened first or how long the action took place. (TB3)

(16) My guest columnist is my daughter Finina who moved back to [the] Philippines with her family. (TB3)

(17) In 1995, a young missionary set foot on [the] Philippine soil. He was on his way to Indonesia but his visa was not yet granted. Since that time, he remained here. (TB3)

(18) This institution was financed by [the] donations solicited by Fr. Cor... (TB3)

(19) Failure to comply with [the] final requirements (TB3)

Wrong article [a/an] before a mass noun [should be $\downarrow$ ]. Before there was $a[\downarrow]$ United States of America or $a[\downarrow]$ UK, they were already using Chinese as medium of instruction in China and Japanese in Japan. (TB1)

\section{Wrong article [the] before a mass noun [should be $\downarrow$ ].}

(1) Difficult terms may be unlocked if you have enough knowledge of the [ $\downarrow$ ] affixations and root words... (TB1)

(2) From the 1950s to the 1970s, educational research was dominated by the behaviorism school of psychology which either gave little emphasis on the $[\downarrow]$ mental processes or made little use of these in scientific study. (TB1)

(3) But now technologies, like video conferencing, allow businesses to cut back on travel costs giving people the $[\downarrow]$ visual as well as the [ $\downarrow$ ] audio feedback... (TB3)

Use of article "the" for a nonspecific reference.

(1) There are three types of cards found in the [a] card catalog: author card, subject card and title card. (TB1)

(2) There are different strategies that the [a] reader can effectively use in reading. (TB1)

(3) All lessons start with the [a] concept map. (TB1)

(4) Besides these functions, the $[\downarrow]$ punctuations have roles to play in sentences, paragraphs and compositions. (TB1)

(5) The $[A]$ period (.) ends a sentence. (TB1)

(6) Parents and teachers can help in noting behavioral changes among the $[\downarrow]$ adolescents. (TB1)

(7) The [A] solid compound is a combination of two words put together written as one word giving rise to a new meaning. The $[A]$ separate compound is likewise a combination of two words also giving rise to a new meaning but written with a space between the words. (TB1)

(8) Infinitives are verb forms composed of the infinitive marker to followed by the [ $\downarrow$ ] verb(s) functioning as nouns, adjectives, or adverbs. (TB1)

(9) Thus, in creative and critical reading, the [a] reader develops a questioning mind...(TB2)

(10) It can be made easier by trying out certain steps with many students and teachers have found helpful in organizing ideas and drafting the [a] composition. (TB2)

(11) Components of the [a] Thesis Statement (TB2) 
(12) The [An] informal debate can also be an occasion to clarify the idea of evidence. (TB2)

(13) In writing the [an] argumentative essay, credibility of sources and logic of presentation are of paramount consideration. (TB2)

(14) The primary purpose of a school is to provide efficiently good education to the [a] student. (TB2)

(15) The $[\downarrow]$ computer already plays a prominent role at schools like Stanford, Cornell, ... (TB2)

(16) Contrast the explanation of euphemism with the definitions of the examples given for euphemisms. Which meaning do you find in the [a] dictionary? (TB2)

(17) College education is the [a] great Filipino dream. (TB2)

(18) A further proof of the strength of family ties and the resilience of the Filipino families is the long-term increases in overseas employment. One of the studies on this subject notes that when the [a] migrant worker decides to leave, his decision is basically a household decision, influenced by the for-the-sake-of-the-family motivation. (TB3)

(19) Television influences the [a] child's learning. (TB3)

(20) Context clues or hints (are) often found in the [a] reading material to help the reader determine the meaning of unfamiliar words. (TB3)

(21) I admire the $[\downarrow]$ scientist(s) for their wisdom and diligence and the Christian community I respect for its vigilance. (TB3)

Use of the article "a/an" for a specific reference. This was during a [the] time when stories proliferated about TROs being sold, $a$ [the] time when losing bidders resorted to freezing the process by seeking a TRO as a matter of course. That was $a$ [the] time when courts became heavily involved in business decisions... That was $a$ [the] time when a Supreme Court Justice no less had to retire in a hurry... (TB1)

\section{Unusual lexical usage.}

(1) Listen to a Library Orientation (library orientation) lecture to be given by the Librarian. Fill out the form below based on the lecture. (TB1)

(2) Write a reflection (paper) on how you can successfully achieve your goals in college using the resources available in school. (TB1)

(3) Tables, graphs, schematics (schematic diagrams), and flow charts usually provide numerical data which will call for lengthy descriptions if they are put into words. (TB1)

(4) Note that Formal and Informal English refers to the styles of expression. One is not more correct (correct) than the other. (TB1)

(5) Each main idea is expanded (expounded) by supporting details. (TB3)

(6) By the time you graduate from (earn) your master's degree, what will you have acquired? (TB3)

(7) By the time I graduate from (earn) my master's degree, I (buy) a car and (learn) to drive it. (TB3)

$\emptyset^{1}$ majority.

(1) Minor damage to the blood vessel in the eye is found in majority of diabetic patients. (TB1)

(2) Through the analysis of the interview transcriptions, findings show that majority of the student teachers prefer the alternate use of both Filipino and English inside their classrooms. (TB1)

\footnotetext{
1 “ $\varnothing ”$ means missing or zero.
} 
Missing conjunctions. Hence, a teacher judges and decides what kind of learning experiences to expose his students to, based on the criterion of relevance to course content, the learning needs of the students, the specific objectives of the particular lesson, as well as on the criterion on functionality, [and] usefulness or applicability to the practice of the discipline the students are in. (TB1)

\section{Perfect tenses.}

\section{Past for present perfect.}

(1) Now, study the summary of the text you just read and be able to show the difference between a summary and a full-blown text. (TB1)

(2) The techniques discussed in this lesson helped me a lot in improving my reading skills... I have learned how to write an effective summary. I have learned how to write a good paraphrase. (TB1)

(3) Finina stayed in the United States for the past fifteen years. (TB3)

(4) One of man's dreams, since he was born, was to discover the secrets of aging. (TB3)

\section{Past perfect for present perfect.}

(1) The lecture had been developed. (TB1)

(2) The lecture about the demands of college life had been very interesting. (TB1)

Past for past perfect. They left the Philippines before their children entered college. (TB1)

Present perfect for present perfect progressive. I have read the newspaper since eight o'clock this morning. (TB3)

Inconsistency in tenses. Did the topic sentence put together the key concepts developed in the text? Do the follow-up sentences mention the key points concerning the concepts in the topic sentence?... Were all the key points included? Do you find unnecessary details included in the text? Did the summary remain faithful to the text, content-wise? (TB1)

\section{Unnecessary use of modals.}

(1) A sample working bibliography entry would look like this. (TB1)

(2) One strategy that uses critical thinking and which can be used in arriving at good decisions would be problem solving. (TB1)

Misplaced and missing verbs.

(1) This proves that no matter how strong one's capacity is to retain information in one's memory, the danger of not being able to recall all the data is always there. (TB1)

(2) Giving directions is one speech function while giving instructions [is] a rhetorical function - both call for clear step-by-step procedure. (TB1)

(3) We will not waver in our commitment to economic reform and fiscal discipline, whatever the political cost [is]. (TB2)

(4) Context clues or hints [are] often found in the reading material to help the reader determine the meaning of unfamiliar words. (TB3)

Missing direct objects.

(1) Capitalize (?) when the person's title follows the name on the address or signature line. (TB1)

(2) Place the blood in a test tube or vial and label (?) with the patient's name. (TB1)

(3) Finally, add 100 grams of cooked macaroni and simmer (?) for at least 10 minutes. (TB1) 
(4) Answer (?) by using the cue words. (TB3)

(5) Can you show (?) to the class? (TB3)

(6) Transform the sentences in Table 1 to question form, then answer (?) with short replies. (TB3)

(7) He asked, “Why do you have to deny (?)?” (TB3)

(8) Now, change the direct speech to reported speech. Answer (?) according to what is called for in the guide. (TB3)

Who vs. whom. Name one official (living or dead) whom you think is/was an epitome of a good public leader/servant? Why do you say so? (TB1)

\section{Unusual spelling.}

(1) Re-write the whole paragraph. (TB1)

(2) A projector and a lap top are now essential equipment in each classroom. (TB1)

(3) It is wise to read your lessons everyday. (TB1)

(4) A spider is a small, insect like creature with eight thin legs. (TB1)

(5) A video-recorder stores pictures and sounds so that they can be seen and heard later. (TB1)

(6) You saw a school mate in the university you have enrolled in but he/she is taking another academic program. Initiate a conversation with him/her. (TB1)

(7) As a student, you would find yourself interacting/communicating everyday with your teachers and classmates and in some occasions, with school administrators and non-academic personnel. (TB1)

(8) Identify which are factual and opinion based. (TB1)

(9) Do not expect your first draft to be well organized and error free. (TB1)

(10) It is a five-storey building on top of a mountain... From the road, it looks like a one-story building because it is built on the slopes of a mountain... (TB1)

(11) Critical thinking is criteria based and is assessed by appeal to criteria. (TB1)

(12) Using a flowchart, provide a time line showing the history and development of critical thinking. (TB1)

(13) Considering that today's youth are tomorrow's work force, market, entrepreneurs, parents, citizens, CEOs, CFOs, wealth creators, and leaders, then investing in their education today will translate to wealth-creation tomorrow. (TB1)

(14) The same is true in multi-media communication. (TB1)

(15) The critical minded social science teacher may, however, use social problems and issues as an area of concern through which critical thinking may challenge student's cognitive ability. (TB1)

(16) Role-play a situation that shows how you do school work in this age of computer technology. (TB2)

(17) More than just a mere tool for communication, cellphones have become the newest canvas for art. (TB2)

(18) What model of cellphone do you have? Why? (TB2)

(19) Another finding based on the same explanation indicates that there are more extended house-holds among the upper classes than in lower classes. (TB3)

(20) Archie works everyday from morning till late afternoon. (TB3)

(21) The government spearheads the anti pollution campaign. (TB3)

(22) Martin used to play tennis everyday. (TB3)

(23) Do you have any idea how life will be in the twenty first-century? (TB3) 
(24) Giving people visual as well as audio feed-back also strengthens long distance personal relationships. (TB3)

(25) Jackie said, that she was busy touching the lives of the underpriviledged. (TB3)

(26) Bats go out of the caves everyday at six in the afternoon in order to look for food. (TB3)

(27) The Christian world can not accept the research result even if (even though, although) the moral issues on it has been resolved. (TB3)

\section{Redundancies.}

(1) Arrange alphabetically the following entries into a list. (TB1)

(2) Read the following paragraphs below. (TB1)

(3) As it is, the form is that of a statement but the function or end-result is that of a question. (TB1)

(4) If the topic sentence gives the effect, the succeeding sentences will show the cause(s) and vice-versa. It is usually common in expository structures. (TB1)

(5) Furthermore, footnotes or endnotes are employed for easy reference as they serve as more additional information printed at the bottom of the page or at the end of the text. (TB1)

(6) I like the color pink. (TB1)

(7) More than just a mere tool for communication, cellphones have become the newest canvas for art. (TB2)

(8) But despite its siren and lights, it had to give way to some of the cars... (TB3)

\section{Punctuations.}

\section{Unnecessary commas.}

(1) Go over the text, The Library. Pick out and write down one sentence that uses verbs for the following: (a) main verb; (b) auxillary verb; (c) linking verb; and (d) modal. (TB1)

(2) Antonia never liked leaving the Philippines, even though most of her siblings did. (TB1)

(3) Declarative sentences are used to make a statement, and to express emotions and reactions. (TB1)

(4) All of these items should be labeled as exhibits, and given an explanatory title. (TB2)

(5) You study the subject from different perspectives, and argue about it. (TB2)

(6) Everybody was waiting for the next event, when the grandson stepped forward. (TB3)

(7) Can you predict what is going to happen next, based on the facts presented in the above paragraph? (TB3)

(8) The teacher said, that the matter occupies space. (TB3)

(9) Jackie said, that she was busy touching the lives of the underpriviledged. (TB3)

\section{Incorrect punctuation marks.}

(1) Explain why you did so? (TB1)

(2) Name one official (living or dead) whom you think is/was an epitome of a good public leader/servant? Why do you say so? (TB1)

(3) A few were privatized and used for commercial real estate development? (TB1)

(4) Relate to the class cases similar to Archie's life in which children are abused or exploited. Use the outline below as your guide: (a) name of the victim; (b) a description of the victim's life and family; (c) form or abuse or exploitation; and (d) assistance extended by people around to help the victim. (TB3)

(5) Transform the sentences in Exercise 7 into simple questions. Then give short replies. For example: The 
driver was beating the traffic light when an ambulance appeared before him? (TB3)

(6) Give three steps or precautions you will take in case of emergencies/situations like the following: Express the future tense in different ways. (TB3)

(7) An adverbial clause is a dependent or subordinate clause that is introduced by a subordinator or linker indicating: time, reason, condition, place, manner, purpose, concession, or consequence. (TB3)

\section{Missing commas.}

(1) Sometimes [,] the length is similar to the original or even longer... (TB1)

(2) A problem is presented, the causes of the problem are given, and finally [,] a solution is suggested (TB1)

(3) The outline in the preceding pages can be of help [,] but you are free to modify it to suit the text. (TB1)

(4) It is an inevitable part of human life [,] but too much of it is unhealthy. (TB2)

(5) Two people in a close relationship normally enjoy doing things for each other [,] but there is a limit to the amount of time and energy most individuals are willing to devote to the person they love. (TB2)

(6) We may disagree among ourselves [,] but let us never lose sight of that greater battle for one people, one country, one Philippines. (TB2)

(7) Furthermore, the book embodies the content of the CHED's recommended outline for an English Plus course, namely: (no colon needed) [,] a vocabulary to prepare freshman students for academic study, and a grammar to enable him to perform communicative functions. (TB3)

(8) Now [,] listen to your partner as he reads out his sentence halves. (TB3)

(9) Write a five-sentence paragraph about the things you used to do when you were in high school. Also [,] explain why you have stopped doing them. (TB3)

\section{Missing question marks.}

(1) If you will write about a place, ask yourself the question(s): "What about this place [?] (What) makes it memorable?" (TB1)

(2) Which voice is preferred for the following text types [?] (TB1)

\section{Missing period.}

(1) The topic is mentioned, then it is restricted, and finally examples or an illustration is given [.] (TB1)

(2) Request the patient to make a fist with the arm extended [.] (TB1)

(3) Loosen the tourniquet [.] (TB1)

\section{Ambiguous statements.}

(1) Learning styles help you understand yourself better. It also gives you an insight on what really works for you and how you can manage your learning. (TB1)

(2) Summary writing entails practice. It is not achieved overnight. To develop such skill more easily, you have to engage in it regularly. (TB1)

(3) Cite the differences in meaning between/among these pairs of words. Work with your seatmate.

amoral-immoral rewind—unwind

abolish—demolish miscast—recast (TB1)

(4) Compare the summary with the paraphrase. What words/structures have been changed? Make a list of these changes below. (TB1) 
(5) Craig and Hopper (1986) mentioned the conditional tense and the conditional perfect to indicate an event predicted to happen in future time depending on a condition that is either expressed in an if clause or implied. (TB1)

(6) Answer the following questions with a partner. Share your discussion with the class. (TB1)

(7) 4. What does this article explicitly say about most Filipinos? 5. Do you agree with him? Justify your answer. (TB1)

(8) After this lesson, you should be able to use the functions of sentences appropriately. (TB1)

(9) Below are statements from different articles. Write $\mathrm{N}$ if they are considered narratives from materials and $\mathrm{E}$ if you think they come from expository materials. (TB1)

(10) Read the following from the article. With a partner, identify the type of structure used in the excerpt, then, answer the questions that follow. (TB1)

(11) Reading structures may either be narrative or expository. (TB1)

(12) Adjectives with more than two syllables are preceded by more and most. (TB1)

(13) Each type of text employs a different kind of vocabulary. For instance, academic texts abound in the use of terms with affixation. (TB1)

(14) Below are complaint letters taken from the "Letters to the Editor" section in type of broadsheet. (TB1)

(15) As it is, nominalization helps you express the same idea in varied ways. It can sometimes make a text sound more written and elegant and the language becomes more impersonal. (TB1)

(16) This is the style when the leader tells his/her group mates what they are supposed to do. (TB1)

(17) This is the manner of presenting the text to indicate the author's point of view or perspective. (TB1)

(18) Aside from making clear your intent or focus, it also serves to guide your readers to the rest of your article. (TB2)

(19) What is the main idea of the text? Is it explicit or implicit? If it is explicit, point out the statement in the text; if it not, formulate the statement. (TB2)

(20) But our competitiveness is greatly endangered today by the global oil crisis. I call on Congress to pass legislation encouraging renewable and indigenous energy. (TB2)

(21) Talk about your first day in the university. Answer the following questions to guide you in your discussion. (TB3)

(22) Changes from the future active to the future passive form. (TB3)

(23) The teacher reads $a$ second time. (TB3)

(24) Change the verbs of the answers in Exercise 2 to the past tense. Use adverbs yesterday (or last, ago, the other day) that denote definite past time. (TB3)

(25) Write either one of your oral talks. (TB3)

(26) Use Exercise 2 as pattern to interview one of your classmates. Then exchange roles. (TB3)

(27) By using a suffix identify the person. (TB3)

(28) Underline the adjective phrase and identify it as prepositional, a participial. (TB3)

(29) Baguio is the Summer Capital of the Philippines. It is a bloom with a variety of flowers through the year. (TB3) 
(30) Climactic order is achieved when the series of ideas are arranged in an ascending order or degree of intensity... (TB3)

\section{Unpluralized nouns.}

(1) After this lesson, you should be able to observe subject-verb and pronoun-antecedent congruence in oral and written discourse. (TB1)

(2) The article entitled A Guide for College Graduates lends itself to affixation. Make a list of words you encountered that use prefixes and suffixes then identify their rootword [root words]. (TB1)

(3) Impromptu speaking can be made less frightening if you follow some suggested formula to organize your thoughts. (TB1)

(4) Accomplish the third and last column after reading the article. (TB1)

(5)... appreciate and respect the opinion of others (TB1)

(6) Since then, not only has educational technology taken great leaps forward, but the advances come when computer provides real solution to real problems. (TB2)

(7) The following excerpts come from the reading selection. Read them carefully and give the meaning of the italicized word. (TB2)

(8) Solve the numbered clues and enter the correct words on the vertical and horizontal grid. (TB2)

(9) Change the verb of the following sentences to the passive form. (TB3)

(10) But what struck me even more than all the new infrastructure and technological advancements was the "me first" mentality... (TB3)

(11) Complete the following sentences with the past form of the verb in parentheses. (TB3)

(12) Women go to church without cover on their head. (TB3)

(13) Do you remember life before pagers, cell phones, fax machines and e-mail? (TB3)

(14) People will be waiting for more surprise in the years to come. (TB3)

(15) Advances in science produce new and better medicine tomorrow. (TB3)

(16) As the teacher reads, identify each of the projected scientific development. (TB3)

Parallelism problems. This will help you how to react to the argument and will help you understand the logic behind the ideas put together. (TB1)

\section{Capitalization problems.}

(1) (if the company owner decides to hire the applicant, then that person is taken in as an employee.) (TB1)

(2) (if and employer finds an employee guilty of a criminal act, then s/he decides to fire/teminate/dismiss the person) (TB1)

(3) (a priest who officiates a nuptial ceremony pronounces a couple to be man and wife) (TB1)

(4) Nothing can motivate a retreatant more than a peaceful and welcoming Retreat House. (TB1)

(5) With a partner, take turns in singling out the difference between the two versions of the text Taking a blood sample. (TB1)

(6) Write a short discourse on any of the following topics using Academic English. (TB1)

(7) The world bank give priority to the third world countries. (TB3)

(8) Match Column A with Column B (you may pair off an item twice). (TB1) 


\section{Discussion}

The goal of the content analysis of three textbooks used by both college English teachers and college English learners is to pinpoint which variety or varieties of English are used and represented in writing them. Textbooks were analyzed primarily because learners are expected to assimilate and conform to what they promote or purport, e.g., rhetorical conventions and usage preferences.

The analysis shows that although the three books differ with respect to organizational structures and content coverage, they are similar in a number of ways. These textbooks aim not only to hone the grammatical competence of the students but also other macroskills like reading, speaking, and writing. It was also found that the writers of these books, who are all Filipinos and English teachers themselves, more ardently promote the local culture and selections authored by Filipino writers. Furthermore, while grammar is taught both deductively and inductively in two of the textbooks analyzed-which makes the approach rule-driven-there is no explicit attempt on the part of the writers to promote the use of a single variety of English—British or American—in oral and written discourses. The cases of inconsistencies in spelling, however, may indicate that the writers recognize the two inner-circle varieties of English.

It is also worthy of note that there have been locally published textbooks like TB1 and TB2 that include contentious issues material to English language learning and existence of local varieties of English. These textbooks, however, contained very little information about the different varieties of English in the world. In other words, little room is devoted specifically to varieties in the textbooks. The treatment of sociolinguistic issues that language teachers and language learners should address either collectively or individually seems superficial and needs a further revisit to be more profound and wider in coverage. The analysis shows that:

There is a need to include more exposure to varieties and variety-related training in ELT to create awareness that English is not monolithic and to provide learners with communicative competence that enables them to effectively communicate in a variety of situations in a changing and increasingly globalised world. (Bieswanger, 2008, p. 9)

It seems safe to conclude now that varieties of English are still marginally represented in textbooks, as has been demonstrated by the content analysis here. Although the number of textbooks analyzed is limited to three, the basic findings of this exploratory study will most likely hold true for other ESL (English as a Second Language) territories.

Findings also reflect that there are distinctive syntactic structures evident in the pages of the three textbooks, and it might be untenable to claim that these structures are simply performance or competence errors. As it is, publishing a textbook requires a tedious and a recursive process of drafting, editing, and proofreading. Hence, before a textbook such as TB1, TB2, and TB3 is published, the presumption is that its contents and language have been meticulously edited and polished. It may therefore be construed that these textbooks present forms considered acceptable and have become part of acrolectal PhE because the writers and editors of these publications presumably have received a more sophisticated level of English proficiency and because they are also language specialists (Peña, 1997).

Although further studies, e.g., corpus analysis, need to be conducted to establish that the foregoing are undoubtedly features of $\mathrm{PhE}$, the presence of these distinctive structures may indicate that there is another variety 
of English that thrives in local textbooks which students may confront, learn, adopt, and exercise in diverse communicative contexts. It must be noted that a great deal of research put forward that curriculum materials, and especially textbooks, significantly influence classroom instruction (Eisenmann \& Even, 2009; Grouws, Smith, \& Sztajn, 2004; Haggarty \& Pepin, 2002). In fact, Bieswanger (2008) posited that many educators now regard textbooks as a "secret curriculum". It may, therefore, be reasonably argued that what the examined textbooks profess and promote—whether explicitly or implicitly—may (re)shape students' behavior. In the case of Filipino ESL learners, their linguistic decisions and syntactic preferences may be (re)shaped by what they read and glean from the textbooks they are provided with. Textbooks, like teachers, have substantial impact on student achievement and choices. They provide examples, illustrations, and notions which learners could adapt and transfer to specific uses. Put more simply, they offer grammatical and functional frameworks or models which both students and teachers could work with. This is why O’Neill (1982) argued that textbooks provide the core language useful to learners from diverse linguistic backgrounds. In the same vein, Noordin and Abdul Samad (2005) argued that "For most teachers, textbooks provide the foundation for the content of lessons, the balance of the skills taught, as well as the kinds of language practice the students engage in during class activities” (para. 1).

Exposure to written or printed texts is crucial in developing linguistic abilities; thus, students are ordinarily asked to explicitly refer to their textbooks. In the Philippines, and perhaps in other countries, textbooks stand as the starting point for much of the language input learners grasp and the language practice transpiring in the ESL classroom. It is therefore sound to speculate that the untypical syntactic variants found in the textbooks they utilize are internalized when used in different communication situations.

Finally, while there is no explicit hint that learners should adhere to a specific norm when they write or speak, the analysis of the three textbooks would show another case of the use of two varieties-American and Philippine English(es). The British Council (2012) stated that AmE uses the present perfect tense less often, e.g., Did you do you're your homework yet?, rarely uses "have got", uses the terms like trash, pants, and diaper, has words that end in—ter and/or rather than—tre and—our, e.g., theater and color, and often uses shorter words like program and catalog. Based on the analysis, the three textbooks bear these features of AmE. It must be noted, however, that these are used alongside the local variety of English as shown in the examples of distinctive structures culled from the textbook pages; thus, it is reasonable to construe that college English textbooks published locally are written in a pluricentric model, i.e., two varieties, a native, and a nonnative English variety.

\section{Conclusions}

The content analysis of three college English textbooks hints at the assumption that English(es) or varieties of English are rarely extensively reflected and discussed in locally published college English textbooks and that Filipino textbook does not seem to strictly to adhere to a single norm, e.g., AmE. The analysis shows that textbook developers, who, most of the time, are also English teachers use distinctive structures in writing. This makes them propagators of two varieties. In this study, these varieties are American and Philippine English(es).

The above findings also raise another string of questions: Which variety must be promoted in locally published English textbooks given the fact that there are features of the local variety in their pages and how must these textbooks incorporate and address the contentious issues that stem from the use and existence of different 
varieties of English? While answering this question seems formidable at the moment, what educators and ELT curriculuralists can initially undertake is to further (re)examine the instructional materials they produce and ask the learners to use. The newer portrait of a communicative competent speaker of English calls for the ability to be familiar with and shift to another English variety or varieties since, to date, there are more nonnative speakers of English they will inevitably come in contact with and to successfully recognize sociocultural and sociolinguistic differences. This aspiration may not be possible if the kind of instruction they receive and the sort of materials they are given are impotent in providing them with the proper training, resources, approaches, and experiences. It is imperative to consider World English(es) as one of the criteria in the selection and evaluation of textbooks. Textbook writers, on the other hand, should overtly include lesssons or topics that would allow the learners to be exposed to a myriad of variety-related issues and prod the learners to engage in meaningful discussions to address them.

\section{References}

Alonsagay, I., \& Nolasco, J. (2010). Adversativity and the get-passive in Philippine and British English: A corpus-based contrastive study. Philippine Journal of Linguistics, 41, 1-13.

Bautista, M. L. (2000). Defining standard Philippine English: Its status and grammatical features. Manila: De la Salle University Press.

Bautista, M. L. (2001). Studies of Philippine English: Implications for English language teaching in the Philippines. Journal of Southeast Asian Education, 2(2), 271-295.

Bautista, M. L. (2011). Studies of Philippine English: Exploring the Philippine component of the international corpus of English. Manila: Anvil Publishing, Inc..

Bieswanger, M. (2008). Varieties of English in current English language teaching. Stellenbosch Papers in Linguistics, 38, $27-47$.

Bolton, K., \& Bautista, M. L. (2008). Philippine English: Linguistic and literary perspectives. Hong Kong: Hong Kong University Press.

Borlongan, A. M. (2008). Tag questions in Philippine English. Philippine Journal of Linguistics, 39(1-2), 109-134.

Borlongan, A. M. (2011). A grammar of the verb in Philippine English (Unpublished doctoral dissertation, De La Salle University, Manila).

British Council. (2012). British English and American English. Retrieved from http://learnenglish.britishcouncil.org/en/grammar-reference/british-english-and-american-english

Dayag, D. T. (2010). Philippine English and college textbooks in oral communication: Exploring the link between the World Englishes paradigm and L2 pedagogy. Philippine Journal of Linguistics, 41, 63-75.

Dita, S. (2011). The grammar and semantics of adverbial disjuncts in Philippine English. In M. L. Bautista (Ed.), Studies of Philippine English (pp. 33-51). Manila: Anvil Publishing, Inc..

Eisenmann, T., \& Even, R. (2009). Similarities and differences in the types of algebraic activities in two classes taught by the same teacher. In J. T. Remillard, B. A. Herbel-Eisenmann, \& G. M. Lloyd (Eds.), Mathematics teachers at work: Connecting curriculum materials and classroom instruction (pp. 152-170). New York: Routledge.

Elo, S., \& Kynga, S. H. (2008). The qualitative content analysis process. Journal of Advanced Nursing, 62(1), 107-115.

Grouws, D., Smith, M., \& Sztajn, P. (2004). The preparation and teaching practices of United States mathematics teachers: Grades 4 and 8. In P. Kloosterman \& F. Lester, Jr. (Eds.), Results and interpretations of the 1990 through 2000 mathematics assessments of the National Assessment of Educational Progress (pp. 221-267). Reston, V.A.: National Council of Teachers of Mathematics.

Gustilo, L. (2011). Modal auxiliaries in Philippine English newspapers: A corpus-based analysis. Philippine ESL Journal, 6, 81-109.

Haggarty, L., \& Pepin, B. (2002). An investigation of mathematics textbooks and their use in English, French and German classrooms: Who gets an opportunity to learn what?. British Educational Research Journal, 28(4), 567-590.

Johansson, M. (2003). Textbooks in mathematics education: A study of textbooks as the potentially implemented curriculum (Licentiate thesis, Lulea University of Technology, Sweden). Retrieved from http://pure.ltu.se/ws/fbspretrieve/362288 
Matsuda, A. (2002). Representation of users and uses of English in beginning Japanese EFL textbooks. JALT Journal, 24(2), 80-98.

Merrill, M. D. (2002). First principles of instruction. Educational Technology Research and Development, 50(3), 43-59.

Noordin, N., \& Abdul Samad, A. (2005). Examining the importance of EST and ESL textbooks and materials: Objectives, content and form. English for Specific Purposes World, 1(9), 4. Retrieved from http://www.esp-world.info/articles_9/textbooks.htm

O’Neill, R. (1982). Why use textbooks?. ELT Journal, 36(2), 104-111.

Peña, P. S. (1997). Philippine English in the classroom. In M. Bautista (Ed.), English is an Asian language: The Philippine context (pp. 87-102). Australia: The Macquarie Library Pty.

Quirk, R., Greenbaum, S., Leech, G., \& Svartvik, J. (1985). A comprehensive grammar of the English language. London: Longman.

Tayao, M. (2008). A lectal description of the phonological features of Philippine English. In M. Bautista \& K. Bolton (Eds.), Philippine English: Linguistic and literary perspectives (pp. 157-174). Hong Kong: Hong Kong University Press.

Uittamo, H. (2009). Global English: Varieties of English in textbooks (Unpublished thesis, Department of Languages, University of Jyväskylä). 